\title{
The Agricultural Matrix and a Future Paradigm for Conservation
}

\author{
JOHN VANDERMEER* $† \ddagger$ AND IVETTE PERFECTO† \\ ${ }^{*}$ Department of Ecology and Evolutionary Biology, University of Michigan, Ann Arbor, MI 48109, U.S.A. \\ †School of Natural Resources and Environment, University of Michigan, Ann Arbor, MI 48109, U.S.A.
}

\section{Introduction}

Land-use policies, especially in tropical zones, are frequently seen as facing three insoluble problems: (1) low or inefficient agricultural production, which leads to (2) clearing of natural habitat for more farmland, which leads to (3) loss of biodiversity (Ausebel 1996; Glokany 1998; Trewavas 2001). The solution to this three-part dilemma is often seen by going backward, so to speak (1) loss of biodiversity can be stemmed if (2) farmers stop clearing natural habitat, which can be done if (3) agricultural production is intensified on land already devoted to agricultural production. The seemingly inescapable conclusion is that intensifying agriculture already underway is the main solution to the problem of biodiversity loss (Green et al. 2005). We argue that this seemingly impeccable framework is wrong and that a more realistic framing suggests a view of conservation that is distinct from more traditional forms. In our view this more-realistic framing must acknowledge the conservation consequences of the agricultural matrix in a landscape framework.

Here, we focus on the issue of land-use policies, especially on the ecological relationship between natural areas and the surrounding agricultural matrix. The way the problem is frequently framed, as a zero-sum game where competition for land is divided between production and conservation, is wrong, as noted by Angelsen and Kaimowitz (2001 and chapters therein). The problem with this framing is that it tacitly assumes a closed system. What normally happens in practice is that when agriculture is intensified in one corner of the world, that very intensification acts as a magnet to attract more producers to the area, which actually leads to more habitat conversion, as demonstrated by Angelson and Kaimowitz (2001). The simple three-part logical sequence is theoret- ically sound but only within the framework of its own assumptions, which apparently are mainly incorrect in the real world (i.e., few if any on-the-ground situations actually represent a closed system) (Vendermeer \& Perfecto 2005).

We suggest that a more useful framing must recognize that (1) in some areas native habitat destruction is currently underway and (2) in other areas native habitat destruction has run its course. In the first situation the focus is properly on deterrence of future natural habitat conversion. But in the second situation there is a tendency to focus on the patches of natural habitat, thinking of the converted habitats as "destroyed" and thus of little interest to conservation. Placing this second category on the back burner is lamentable given what is now understood about ecology at a large scale. When framed properly a vision of conservation emerges that shifts the focus from the remaining patches of natural habitat to the matrix in which they occur.

\section{When Habitat Destruction is Ongoing}

In the first situation, where habitat destruction is currently underway, it is most frequently the case that natural habitat is being cleared mainly to create farms (Allen \& Barns 1985; Myers 1993; Ranjan \& Upadhyay 1999). This clearing is done by landless or land-poor peasants to establish small family farms or by already land-rich people to further accumulate riches in a speculative economic environment. The assumption that further land clearing is inevitable because of either inefficient agricultural production or a more globally envisioned need for more food is wrong. The world already produces more food than it consumes (Alexandratos 1999; Dyson 1999), and there is 
general agreement among conventional development experts as well as so-called hunger activists that inability to purchase readily available food is normally the problem, not absolute abundance of food, certainly not at the global level and only rarely at a regional level (Moore Lappé et al. 1998). Indeed, even in the face of some of humanity's most famous famines, food was exported away from the famine victims (Polanyi 1944; Davis 2001).

Farmers, as well as academic agricultural economists, note that the principal problem in agriculture today is overproduction, which leads to low commodity prices (Johnson \& Quance 1972; Cochrane 2003); thus, putting yet more land in production is economically absurd from a regional planning perspective. A potential, if currently impractical, solution to the problem would be to stop land speculation and ensure that the landless obtain either access to sufficient land to make a living or opportunities for employment in other economic sectors.

Cuba and Puerto Rico can be illustrative in this respect. In Cuba the socialist revolution eliminated land speculation and implemented a land reform that, combined with the provision of alternative employment for the landless, reduced the rates of deforestation (Perera Puga \& Rosabel González 1986; Levins 1990; Santana 1991). Similarly, although under very different political and economic arrangements, in Puerto Rico deforestation was stopped and even reversed when the country shifted from agriculture to manufacturing (Grau et al. 2003; Aide \& Grau 2004). Underlying assumptions on the inevitability of social inequality certainly create significant barriers to such solutions. If conservationists could join the chorus of the many political actors striving for land reform, it would ultimately help the cause of conservation (e.g., Cullen et al. 2005).

\section{After Habitats Are Converted}

In the second situation, where habitat conversion has already run its course, what remains is a landscape of fragments in a matrix of production systems. It is likely that this will be the situation in the near future the world over. After all of the conceivable parks and reserves are established, it is probable that the majority of the world's biodiversity (including nematodes, arthropods, and the other small things that "run the world" [Wilson 1987]) will exist in the fragments of remaining habitats that exist within the agricultural matrix (Tscharntke et al. 2002). Ecological research over the past decade has emphasized the "meta" nature of preserving biodiversity in this sort of landscape (e.g., Opdam 1991; Hanski 1999; Perfecto \& Vandermeer 2002). Specifically, local extinctions inevitably happen in fragments, a well-established fact based on the vast amount of empirical research motivated by the theories of island biogeography and metapopula- tions (now including metacommunities) (e.g., Fischer \& Stöcklin 1985; Burkey 1989; Bolger et al. 1991; Stratford \& Stouffer 1999). Although small fragments would generate local extinctions, we now understand that extinctions are likely even in large fragments (Newmark 1995; Ferraz et al. 2003). As the theory states and empirical work confirms, regional extinctions will occur if there is no interfragment migration to balance the inevitable local extinctions. A focus on the matrix, through which these migrations must occur, is thus required if we are serious about solving the extinction crisis (Burkey 1989; Hanski 1999; Fischer et al. 2006), and that matrix is usually an agroecosystem of some sort.

The past several decades have seen a great deal of research that challenges the basic assumptions of the conventional agricultural system that developed since the end of WWII. The chemically intensive system causes its own environmental problems (Dinham 1993; Matson et al. 1997), and the claim that such a system is a necessity for feeding the world is wrong (Clark et al. 1999; Bunch 1999; Badgley et al. 2006). Rather, a more ecologically sound form of agriculture has increasingly been promoted by many producers and planners. It is not our intention to enter the debate on reforming agriculture toward a more ecological form-that discussion is long and has been taken up by many (Trewavas 2001; Badgley et al. 2006). Our reason for noting this is that much of the alternative agriculture movement promotes the idea of creating structures within agroecosystems that are much more like the original habitat than is normal under a conventional system (Soule \& Piper 1992, Jackson \& Jackson 2002). If this is true, and it is almost certainly true for tropical areas, the alternative agroecological matrix would be a high-quality matrix from the point of view of allowing migration among fragments.

An example of a highly fragmented natural habitat is the Atlantic rain forest of southeastern Brazil. Popularly thought to be over 90\% destroyed (Saatchi et al. 2001), this habitat is cited as one of the most threatened in the world. A recent study (Hirsch 2003), based on satellite images, shows that in one river basin in the Atlantic forest (the Rio Doce) approximately 1 million ha remain in forest, almost $15 \%$ of the total area, but, with the exception of a large state park, virtually all are small fragments $(28,240$ fragments larger than 1 ha were counted). Nevertheless, this same study shows that almost all the matrix between these fragments is either sun coffee or open pasture, neither of which contains trees as a part of the production system and both of which likely preclude much interfragment migration of most organisms.

The problem here is not in ensuring that the extant fragments remain. That has already been done. The problem is creating a matrix that will allow migration among the fragments to stem the inevitable tide of local extinctions becoming regional. If the well-known technologies of organic and shade coffee (e.g., Perfecto et al. 1996; 
Moguel \& Toledo 1999; Perfecto \& Armbrecht 2003), silvopastoral systems (Ashton \& Montagnini 1999), and other agroforestry systems were to be pursued, which could easily occur with the proper political incentives and technical advise, it is likely that the permeability of the matrix would increase dramatically. It is not a surprise that it is precisely in the Atlantic forest region of Brazil, one of the most highly fragmented habitats in the tropics, where environmental nongovernmental organizations and land-reform activists are collaborating to develop farming systems and landscape structures that are compatible with the conservation of biodiversity (Cullen et al. 2005), with a major focus on the role of the agricultural matrix as a migration pathway. These initiatives and collaborations represent the best hope for conserving biodiversity in areas of the world where most of the natural habitat has already been converted to agriculture or other land-use systems.

Thus, in the environment likely to be common in the future, the focus needs to be on the agricultural matrix, not only as a potential reserve of biodiversity (Pimentel et al. 1992; Perfecto et al. 1996; McNelly \& Scherr 2002) but perhaps more importantly as the medium through which migrations must occur to ward off the process of turning isolated local extinctions to regional or even global extinctions (Burkey 1989; Vandermeer \& Carvajal 2001; Vandermeer et al. 2006). A focus on the landscape (or the countryside [Daily 2001]) and within that on the agroecological matrix (Vandermeer et al. 2006) is thus not only worthy for its environmental soundness but also it is necessary for the fundamental goals of biodiversity conservation.

\section{Literature Cited}

Aide, T. M., and H. R. Grau. 2004. Globalization, migration and Latin American ecosystems. Science 305:1915-1916.

Alexandratos, N. 1999. World food and agriculture: outlook for the medium and longer term. Proceedings of the National Academy of Science 96:5908-5914.

Allen, J. C., and D. F. Barnes. 1985. The causes of deforestation in developing countries. Annals of the Association of American Geographers 75:163-184.

Angelsen, A., and D. Kaimowitz, editors. 2001. Agricultural technologies and tropical deforestation. CABI Publishing, Oxon, United Kingdom.

Ausebel, J. H. 1996. Can technology spare the Earth? American Scientist 84:166-178.

Ashton, M. S., and F. Montagnini, editors. 1999. The silvicultural basis for agroforestry systems. CRC Press, Boca Raton, Florida.

Badgley, C., J. Moghtader, E. Quintero, E. Zakem, M. J. Chappell, K. Avilés-Vázquez, A. Samulon, and I. Perfecto. 2006. Organic agriculture and the global food supply. Renewable Resources and Food Systems: in press.

Bolger, D. T., A. C. Alberts, and M. E. Soulé. 1991. Occurrence patterns of birds species in habitat fragments: sampling, extinction, and nested species subsets. The American Naturalist 137:155-166.

Bunch, R. 1999. More productivity with fewer external inputs: Central American case studies of agroecological development and their broader implications. Environment Development and Sustainability 1:219-233.
Burkey, T. V. 1989. Extinction in nature reserves: the effect of fragmentation and the importance of migration between reserve fragments. Oikos 55:75-81.

Clark, S., K. Klonsky, P. Livingston, and S. Temple. 1999. Crop yield and economic comparisons of organic, low-input, and conventional farming systems in California's Sacramento Valley. American Journal of Alternative Agriculture 14:109-121.

Cochrane, W. W. 2003. The curse of American agricultural abundance: a sustainable solution. University of Nebraska Press, Lincoln.

Cullen, L. Jr., K. Alger, and D. M. Rambaldi. 2005. Land reform and biodiversity conservation in Brazil in the 1990: conflict and the articulation of mutual interests. Conservation Biology 19:747-755.

Daily, G. 2001. Ecological forecasts. Nature 411:245.

Davis, M. 2001. Late Victorian holocausts: El Niño famines and the making of the Third World. Verso, London.

Dinham, B. 1993. The pesticide hazard. Zed Books, London.

Dyson, T. 1999. World food trends and prospects to 2025. Proceedings of the National Academy of Science, USA 96:5929-5936.

Ferraz, G., G. L. Russell, P. C. Stouffer, R. O. Bleregaard Jr., S. L. Pimm, and T. E. Lovejoy. 2003. Rates of species loss from Amazonian forest fragments. Proceedings of the National Academy of Science, USA 100:14069-14073.

Fischer, M., and J. Stöcklin. 1985. Local extinctions of plants in remnants of extensively used calcareous grasslands 1950-1985. Conservation Biology 11:727-737.

Fischer, J., D. B. Lindenmayer, and A. D. Manning. 2006. Biodiversity, ecosystem function, and resilience: ten guiding principles for commodity production landscapes. Frontiers in Ecology and the Environment 4:80-86.

Goklany, I. M. 1998. Saving habitat and conserving biodiversity on a crowded planet. BioScience 48:941-953.

Grau, H. R., T. M. Aide, J. K. Zimmerman, J. R. Thomlison, E. Helmer, and X. Zou. 2003. The ecological consequences of socioeconomic and land-use changes in postagriculture Puerto Rico. Bioscience 53:1159-1168.

Green, R. E., S. J. Cornell, J. P. W. Scharlemann, and A. Balmford. 2005 Farming and the fate of wild nature. Science 307:550-555.

Hanski, I. 1999. Metapopulation ecology. Oxford University Press, Oxford, United Kingdom.

Hirsch, A. 2003. Avaliação da fragmentação do habitat e seleção de areas prioritárias para a conservação dos primates na Bacia do Rio Doce, Minas Gerais, através da aplicação de um sistema de informações geográficas. PhD thesis. Instituto de Ciéncias Biológicas, Universidade Federal de Minas Gerais, Belo Horizonte, Brazil.

Jackson, D. L., and L. L. Jackson. 2002. The farm as natural habitat: reconnecting food systems with ecosystems. Island Press, Washington, D.C.

Johnson, G. L., and Q. L. Quance. 1972. The overproduction trap in US agriculture. Johns Hopkins University Press, Baltimore, Maryland.

Levins, R. 1990. The struggle for ecological agriculture in Cuba. Capitalism, Nature and Socialism 5:121-141.

Matson, P. A., W. J. Parton, A. G. Power, and M. J. Swift. 1997. Agricultural intensification and ecosystem properties. Science 277:504-509.

McNeely, J. A., and S. J. Scherr. 2002. Ecoagriculture: strategies to feed the world and to save wild biodiversity. Island Press, Washington, D.C.

Moguel, P., and V. M. Toledo. 1999. Biodiversity conservation in traditional coffee systems of Mexico. Conservation Biology 13:11-21.

Moore Lappé, F, J. Collins, and P. Rosset. 1998. World hunger twelve myths. Food First Books, Oakland, California.

Myers, N. 1993. Tropical forests: the main deforestation fronts. Environmental Conservation 20:9-16.

Newmark, W. D. 1995. Extinction of mammal populations in western North American national parks. Conservation Biology 9:512-526.

Opdan, P. 1991. Metapopulation theory in habitat fragmentation: a review of holartic breeding bird studies. Landscape Ecology 5:93-106.

Perera Puga, A., and P. Rosalba González. 1986. Sistema nacional de 
áreas protegidas de la República de Cuba. Taller Internacional sobre Sistemas Nacionales de Areas Protegídas, Caracas, Venezuela. COMARNA, La Habana, Cuba.

Perfecto, I., and I. Armbrecht. 2003. The coffee agroecosystem in the Neotropics: combining ecological and economic goals. Pages 159194 in J. H. Vandermeer, editor. Tropical agroecosystems. CRC Press, Boca Raton, Florida.

Perfecto, I., and J. Vandermeer. 2002. The quality of agroecological matrix in a tropical montane landscape: ants in coffee plantations in southern Mexico. Conservation Biology 16:174-182.

Perfecto, I., R. Rice, R. Greenberg, and M. Van der Voolt. 1996. Shade coffee as refuge of biodiversity. BioScience 46:589-608.

Pimentel, D., U. Stachow, D. A. Takacs, and H. W. Brubaker. 1992. Conserving biological diversity in agricultural/forestry systems. BioScience 42:354-362.

Polanyi, K. 1944. The great transformation. Beacon Press, Boston.

Ranjan, R., and V. P. Upadhyay. 1999. Ecological problems due to shifting cultivation. Current Science 77:1246-1250.

Saatchi, S., D. Agosti, K. Alger, J. Delabie, and J. Musinsky. 2001. Examining fragmentation and loss of primary forest in the Southern Bahian Atlantic forest of Brazil with radar imagery. Conservation Biology 15:867-875.

Santana, E. 1991. Nature conservation and sustainable development in Cuba. Conservation Biology 5:13-16.
Soule, J. D., and J. K. Piper. 1992. Farming in nature's image. Island Press, Washington, D.C

Stratford, J. A., and P. C. Stouffer. 1999. Local extinctions of terrestrial insectivorous birds in a fragmented landscape near Manaus, Brazil. Conservation Biology 13:1416-1423.

Tscharntke, T., I. Steffan-Dewenter, A. Kruess, and C. Thies. 2002. Contribution of small habitat fragments to conservation of insect communities of grassland-cropland landscapes. Ecological Applications 12:354-363.

Trewavas, A. J. 2001. The population/biodiversity paradox. Agricultural efficiency to save wilderness. Plant Physiology 125:174-179.

Vandermeer, J. H., and R. Carvajal. 2001. Metapopulation dynamics and the quality of the matrix. The American Naturalist 158:211-220.

Vandermeer, J. H., and I. Perfecto. 2005. The future of farming and conservation. Science 308:1257-1258.

Vandermeer, J. H., I. Perfecto, S. Philpott, and M. J. Chappell. 2006. Reenfocando la conservación en el paisaje: La importancia de la matriz. In press in J. Saenz, and C. Harvey, editors, Evaluación y conservación de la biodiversidad en paisajes fragmentados en Mesoamerica. Editorial de la Universidad Nacional Autonoma de Costa Rica, San Jose, Costa Rica.

Wilson, E. O. 1987. The little things that run the world (the importance and conservation of invertebrates). Conservation Biology 1:344346.

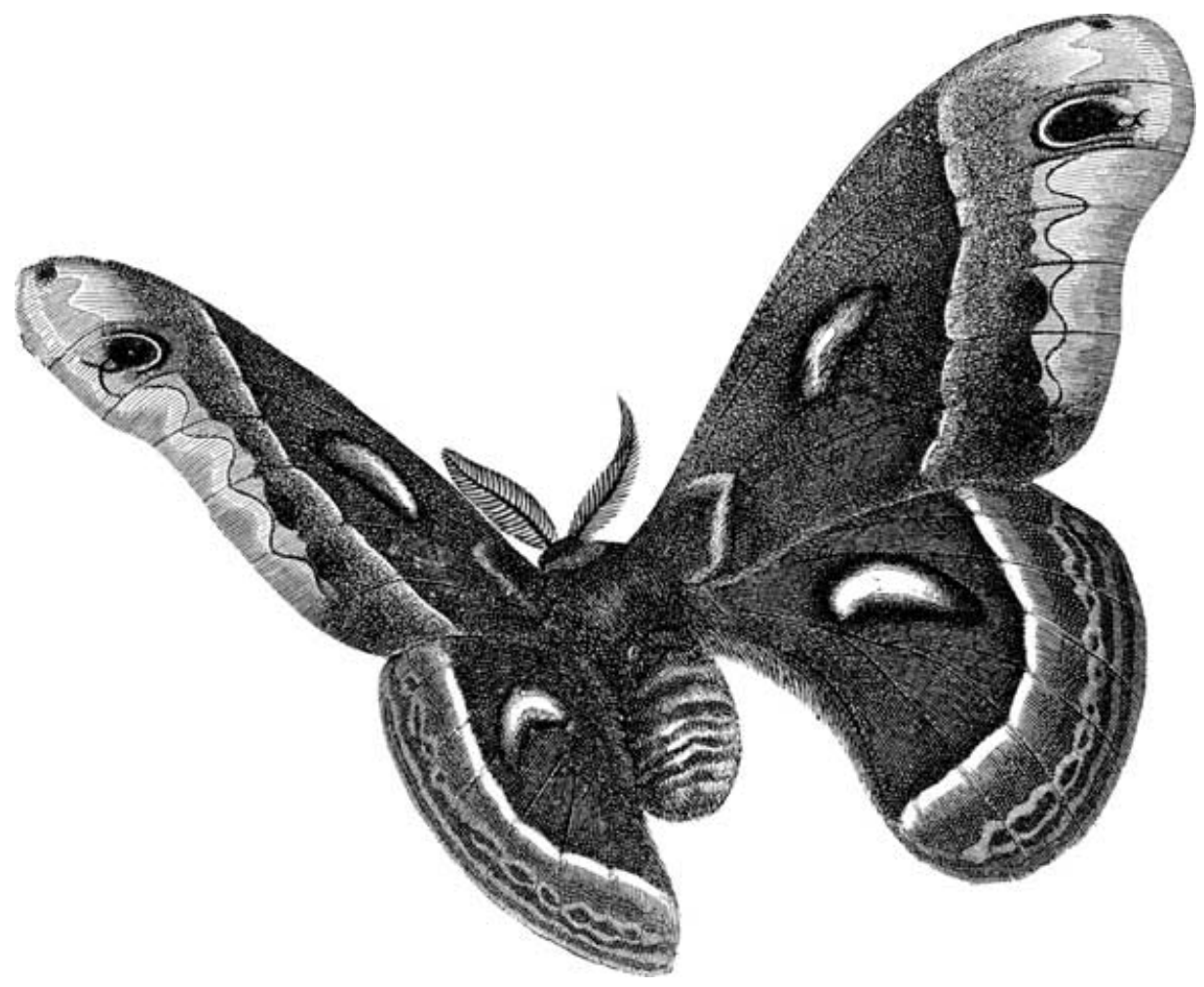

